\title{
Features and Pricing of Weather Index Insurance-based on rice temperature index insurance in Wangqing county
}

\author{
Jing Lu \\ Insurance School, \\ Central University of Finance and Economics, \\ Beijing 100081
}

\begin{abstract}
In recent years, weather risk has become a major risk for agricultural production, especially for China which has six climate zones and has complex terrain. Due to the high risk of adverse selection, high moral hazard, and high underwriting and claim reasons, traditional agricultural insurance has been unable to deal with weather risk. Weather index insurance immediately emerged. In the paper, after studying the features and pricing methods, it selects Wangqing county 1998-2012 fifteen years meteorological data and rice yield data, chooses the temperature as an index, and use the value of the average daily temperature data and production data to determine the premium rates.
\end{abstract}

Key words: Weather index insurance, Pricing method, Temperature Anomaly, Nonparametric Estimation

\section{INTRODUCTION}

Weather index insurance refers to the indexation of the impact of one or more climatic conditions on the extent of crop losses. It was born in the late 1990s. Its advantages such as objectivity and transparency in the process of verification and settlement, effective avoidance of adverse selection and reduction of moral hazard make it obviously superior to traditional agricultural insurance. Therefore, weather index insurance products have become a new attempt to spread weather risk. With the vigorous promotion of the World Bank, it has made tremendous progress in developing countries as a new way of risk dispersion. In 2003, the World Bank piloted the Rainfall Index Insurance in India for the first time, and its success shows a high feasibility. Inspired by this pilot project, insurance based on more weather indices (such as flood index, drought index, high temperature index, rainfall index, etc.) has been proposed one after another.

At the end of 2007, Shanghai Anxin Agricultural Insurance Company launched China's first pilot weather index insurance for watermelon in Nanhui. Although the pilot area is small, its introduction undoubtedly brings new ideas and opportunities to China's agricultural insurance. In 2012, China's Insurance Regulatory Commission proposed to strengthen the innovation of agricultural insurance products to meet the sustainable and stable development of agriculture, and actively develop and promote weather index insurance products. In 2014, the Opinions of the State Council on Reform and Development of Insurance Industry clearly pointed out that we should actively and steadily promote pilot projects, develop multi-form and multi-channel agricultural insurance, and expand the coverage of agricultural insurance, which brings new opportunities to weather index insurance and even agricultural insurance.

At present, China's weather index insurance and its operation status as shown in Table 1. 
Table1 Weather Index Insurance in China

\begin{tabular}{llrl}
\hline ype & Insurance compeny & Year & Operation status \\
\hline Jatermelon plum rains intensity index ins. & AnXin Agricultural ins. CO.,Ltd & 2007 & Pilot operated in Shanghai. \\
ice Planting Weather Index ins. & Guoyuan Agricultural ins. CO.,Ltd & 2009 & Pilot operated, small-scale promotion. \\
auliflower Weather Index ins. & AnXin Agricultural ins. CO.,Ltd & 2009 & At the stage of development. \\
Jinter Vegetables Cost Price ins. & AnXin Agricultural ins. CO.,Ltd & 2010 & Pilot operated, small-scale promotion. \\
piculture drought weather index ins. & PICC Beijing Branch & 2011 & At the stage of development. \\
range Low Temperature Index ins. & PICC Jiangxi Branch & 2011 & Pilot operated in Nanfeng, Jiangxi Province. \\
obacco Frost and Flood Disaster Index ins. & China life P\& C ins. CO.,Ltd & 2012 & Pilot operated in Changting, Fujian Province. \\
ummer Vegetables Price index ins. & PICC Zhangjiagang Branch & 2012 & Pilot operated in Nanfeng, Jiangsu Province. \\
ireen vegetable field transaction price index ins. AnXin Agricultural ins. CO.,Ltd & 2013 & Pilot operated in Chongming, Shanghai \\
Jind Index Aquaculture ins. & PICC & 2013 & Pilot operated in Dalian, Liaoning Province. \\
ig Price Index ins. & Anhua Agricultural ins. CO.,Ltd & 2013 & Pilot operated in Beijing \& Shandong Province \\
egulatory Fattening Pig Price Index ins. & AVIC Groupama ins. (China) Co. Ltd 2013 & Pilot operated in Sichuan Province. \\
anana Tree Wind Disaster Index ins. & PICC Hainan Branch & 2013 & At the stage of development. \\
Iaize Drought Weather Index ins. & AVIC Groupama ins. (China) Co. Ltd 2014 & Pilot operated in Liaoning Province. \\
ayberry Picking Period Rainfall Weather ins. & PICC & 2015 & Pilot operated in Zhejiang Province. \\
herry Precipitation Index ins. & PICC & 2015 & Pilot operated in Liaoning Province. \\
oquat Low Temperature Index ins. & CPIC & 2016 & Pilot operated in Zhejiang Province. \\
ice High Temperature Index ins. & PICC & 2016 & Pilot operated in Hubei Province. \\
\hline
\end{tabular}

China has a wide latitude span, complex terrain and thousands of meteorological conditions. How to design weather index insurance products that meet local climate conditions and market needs is a difficult problem for China to take root and promote. Index design and pricing is the key. It not only affects the insurance company to determine a relatively fair, reasonable and sufficient rate, to prevent the pricing risk of insufficient rate, but also guides the product design process. By studying the relationship between local climate and crop yields, we can design suitable insurance products and determine the trigger cap, deductible and other key terms of insurance policies. Therefore, taking rice production in Wangqing County as an example, this paper takes the design and pricing of weather index insurance as the research subject, which has profound theoretical value and practical significance.

\section{FEASIBILITY OF PROMOTING WEATHER INDEX INSURANCE IN CHINA}

Weather index insurance, also known as 'Weather-index Insurance'. 'Index-based weather Insurance' or 'Index Insurance for Weather Risk', is born in the 20th century, the late 90s, it refers to one or a few degrees of loss of crops climatic conditions affect indexation of insurance. It describes the degree of crop losses by one or several climatic conditions. When the index reaches a certain level (that is, the trigger value), the insured can get the appropriate level of compensation according to the written contract.

\section{Adverse conditions}

First, the lack of hardware facilities. The distribution of meteorological stations in China is not enough to ensure that there are meteorological stations in every natural area, and the demand for meteorological observation cannot be insured. Moreover, because of the complex terrain and terrain in China, it can not guarantee that a region is affected by the same climate conditions, and it also puts forward a test to the fairness of weather index insurance products.

Second, insufficient awareness of insurance and insufficient effective demand. Farmers have insufficient purchasing power, insufficient effective purchasing demand, and the traditional concept of "feeding on the sky" has been deeply rooted. As a new type of agricultural insurance products, weather index insurance is more difficult for farmers to generally accept. 
Thirdly, the government's support is insufficient. The government has not introduced subsidies for weather index insurance. Without subsidies, the process of implementing weather index insurance will be more difficult and long.

Fourthly, the data are not publicly available and have poor reliability.

\section{Favorable conditions}

First, China's insurance market is constantly improving. The number of insurance companies in our country has exceeded 100 . With the continuous enrichment of market participants and the increasingly fierce competition, insurance companies continue to innovate products and improve services to provide favorable support for the design and pricing of weather index insurance.

Second, the improvement of insurance supervision. The CIRC has formulated standardized rules in insurance product reporting, market access withdrawal, solvency management, etc. It has better managed insurance companies and insurance products and provided regulatory support for weather index insurance design.

Third, the effective guidance of policy. The guiding role of policy and the demonstration role of pilot projects have increased farmers' willingness and possibility to purchase weather index insurance, a new type of agricultural insurance.

Fourth, the emergence of professional and technical personnel such as actuarial insurance. At present, these related professional technologies have been greatly improved in China, and the training of relevant professional and technical personnel has also formed a scale.

To sum up, this paper holds that China has preliminary objective conditions for developing and promoting weather index insurance, and can design and develop products according to regional climate characteristics and promote them in a large scale in rural areas.

\section{PRICING METHOD OF WEATHER INDEX INSURANCE}

At present, there are three main pricing methods in China's academic theory and practice of insurance companies, namely empirical pricing method, distribution fitting method and dynamic modeling method.

\section{Empirical Pricing Method}

Empirical pricing method is a pricing method that collects historical loss data of some weather index insurance in the past several years (such as 50 years) and makes pricing based on empirical data. It is also a more traditional pricing method for weather index insurance. Specifically, after obtaining the temperature data of the historical crop growth period (the whole period from transplanting to maturity), the insurance company calculates the annual loss of the insurance company and calculates the premium charged under the current trigger conditions and compensation standards.

This pricing method is simple to calculate and easy to understand and accept by insurance companies and practitioners. At the same time, its shortcomings are obvious. Empirical pricing method needs a long period of historical data. Because of the restrictions and constraints of various conditions in our country, even if there were data 50 years ago, it is not necessarily the same as the statistical methods and measuring instruments of data at the present stage. Whether it has comparability is still questionable. In the process of using historical data, in fact, 
it implies that "the future is similar to the historical situation, and historical data can be very good". The assumption that "good represents the future" is unfounded and unreasonable, and that historical data do not take into account the trend changes of climate conditions and cannot cover all extreme weather conditions.

\section{Distribution Fitting Method}

Distribution fitting method is to fit the probability distribution curve of the previous empirical data and determine the pure premium price of the weather index insurance as the average value of the statistical distribution of the fitting curve. It improves the traditional empirical pricing method by introducing probability distribution, and evaluates the occurrence probability and loss of extreme climate events beyond the existing historical data.

In addition, the confidence interval of the mean can be calculated by fitting distribution. The width of the interval determines the volatility of pricing, and then affects the level of premium risk appendix. The wider the confidence interval, the higher the volatility of pricing, and the higher the relative risk appendix level. At the same time, the pricing method also has its inherent shortcomings, that is, like empirical pricing method, it does not take into account the trend factors of climate conditions.

\section{Dynamic Modeling Method}

Dynamic modeling method is a pricing method for weather index insurance by dynamically modeling original meteorological data and predicting future meteorological conditions. Under this method, the original meteorological data are divided into trend components and random components: for trend components, the least square method is used to fit the trend equation with trend and periodic terms; for random components, the time series technology is used to model the correlation of meteorological data in adjacent periods.

When the whole dynamic model is built and the fitting results are good, the model can be used to predict the meteorological conditions in the appropriate time period in the future. For example, a series of future rainfall series is simulated by stochastic simulation technology, and the rainfall series is used to analyze the possible compensation situation in the next year, and the average compensation is the net premium of the weather index insurance.

Compared with the first two pricing methods, the dynamic modeling method has obvious advantages. This method makes full use of the historical data information of weather conditions, makes up for the shortcomings of the first two pricing methods, and takes into account the trend changes of climate conditions, so it can predict the future well. At the same time, this method also has some shortcomings, such as high requirement for the modeling technology and accuracy of actuaries, high requirement for the quality of historical data, and the complexity and instability of parameters in the actual modeling process may affect its practicability and promotion. Besides those who specialize in this work, other people may not fully understand this method and lack of testing machines system and measurement criteria.

\section{Index selection}

\section{EMPIRICAL RESEARCH}

\section{Data sources}

The rice yield data of Wangqing County from 1998 to 2012 and the data of temperature, rainfall and relative humidity from May to October come from the Yearbook of statistics and the local Agrometeorological station and meteorological information center. Wangqing County is located in the Northeast Plain, which is the second largest county in the province. It is rich in natural resources. Its rice planting has a long history and a wide area. Therefore, the design of 
weather index insurance for rice in Wangqing County has strong representativeness and practicability.

\section{Method}

SPSS, Excel and other software were used to analyze the temperature, rainfall, relative humidity and other observed data of rice growth period in Wangqing County, and to judge the data quality.

\section{Design Principles and Selection Basis of Index}

a) Meteorological factors which are less affected by human factors should be selected for the index.

b) The index should select relatively stable meteorological factors, which fluctuate less between years and fit well with historical data.

c) The index should be relatively simple and easy to understand and popularize.

d) Meteorological indicators directly affecting crop growth, such as temperature, rainfall and relative humidity, should be selected.

In this paper, the index was determined by a thorough discussion with local agricultural experts, who believed that rice production was related to the weather conditions such as temperature, rainfall and relative humidity during its growth period. However, because the county was located in the northeast of China, rice production was most sensitive to temperature, so temperature was finally chosen as the index in this paper.

\section{Statistical analysis of production data}

From the biological point of view, the yield of crops including rice is generally divided into three parts: trend yield, climate yield and random error. Among them, trend yield is the longterm periodic yield component reflecting the level of productivity development, also known as technical yield. With the improvement of technological level, agricultural productivity has been greatly improved, and the trend yield of rice has gradually increased. Climate yield is the fluctuating yield component affected by short-term periodic change factors dominated by climatic factors, also known as meteorological yield. Error refers to the unexplained part formed by random factors other than trend variables and climate variables. Random error is not considered in this study. In this paper, the effect of temperature change on rice climate yield was studied.

\section{Statistics of the Average Yield of Rice}

In this paper, the original data of rice yield in Wangqing County are sorted out, and the average rice yield (kg/ha) between 1998 and 2012 is obtained. The data results are shown in Table 2 below. 
Table 2 Average Yield of Rice of Wangqing county in1998-2012

\begin{tabular}{|c|c|c|c|c|}
\hline Year & $\begin{array}{c}\text { Area } \\
\text { (hectares) }\end{array}$ & $\begin{array}{c}\text { Output } \\
\text { (tons) }\end{array}$ & $\begin{array}{c}\text { Average yield } \\
\text { (ton/ha) }\end{array}$ & $\begin{array}{c}\text { Average yield } \\
\text { (kg/ha) }\end{array}$ \\
\hline 1998 & 5298 & 7617 & 1.43771 & 1437.712 \\
\hline 1999 & 5301 & 27024 & 5.09791 & 5097.906 \\
\hline 2000 & 5298 & 24197 & 4.56720 & 4567.195 \\
\hline 2001 & 5248 & 25023 & 4.76810 & 4768.102 \\
\hline 2002 & 5118 & 13488 & 2.63540 & 2635.404 \\
\hline 2003 & 4230 & 1156 & 0.27329 & 273.2861 \\
\hline 2004 & 4519 & 22863 & 5.05931 & 5059.305 \\
\hline 2005 & 4699 & 26255 & 5.58736 & 5587.359 \\
\hline 2006 & 4797 & 27096 & 5.64853 & 5648.53 \\
\hline 2007 & 5152 & 23660 & 4.59239 & 4592.391 \\
\hline 2008 & 4990 & 29366 & 5.88497 & 5884.97 \\
\hline 2009 & 5164 & 19808 & 3.83579 & 3835.786 \\
\hline 2010 & 5223 & 26424 & 5.05916 & 5059.161 \\
\hline 2011 & 5219 & 28823 & 5.52271 & 5522.705 \\
\hline 2012 & 4825 & 28301 & 5.86549 & 5865.492 \\
\hline
\end{tabular}

Among them,

The average yield is equal to rice yield divided by planting area.The average yield data in Table 1 are plotted as a broken line, as shown in Figure 1 below.

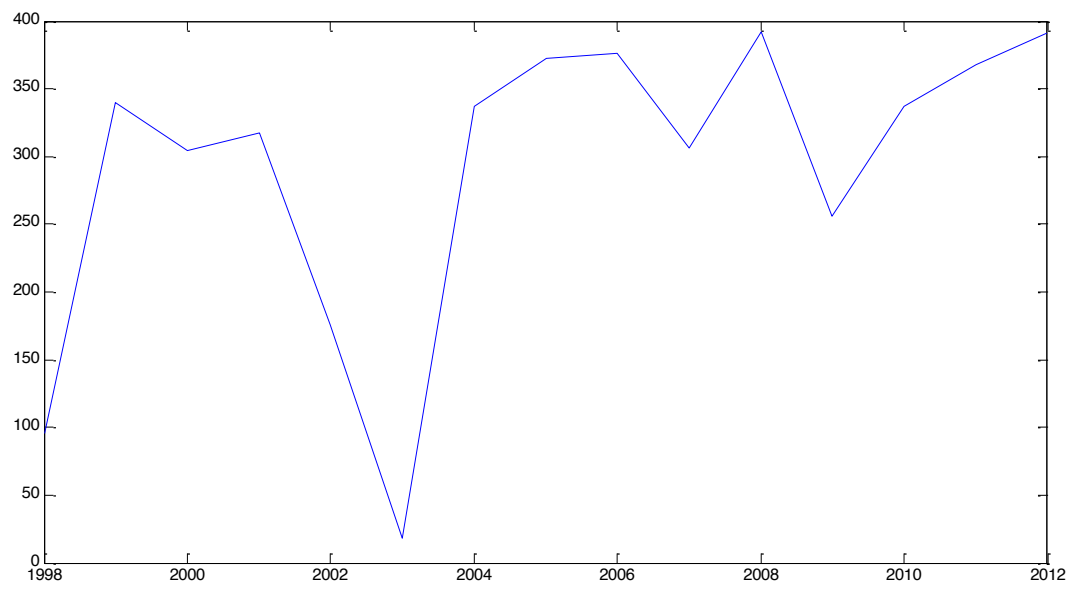

Figure 1 Average Yield of Rice of Wangqing county in 1998-2012 


\section{Statistics of the Average Climate Yield of Rice}

In this paper, the secondary exponential smoothing method is used to eliminate the trend of the original yield data, and the climatic yield is obtained as shown in Figure 2.

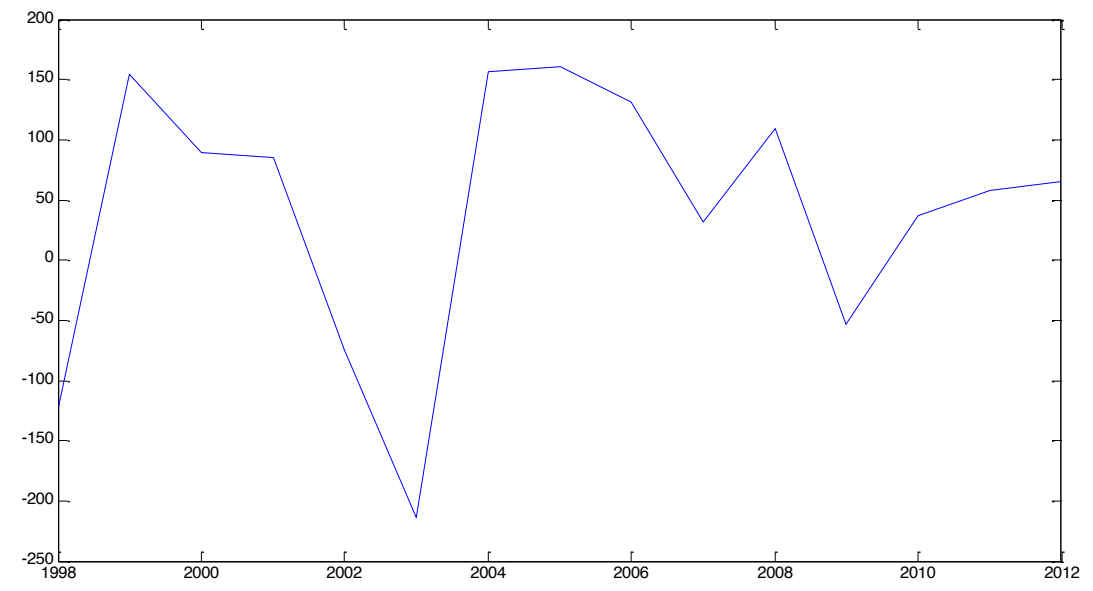

Figure1 Average climate yield of rice of Wangqing county in1998-2012

\section{Statistical results of temperature data Statistical data of temperature}

In the selection of the time period of temperature statistics, through practical investigation and expert interviews, this paper learned that the transplanting period of rice in Wangqing County is from May 20 to May 30, and the ripening period is from September 20 to October 1. According to the actual environment and conditions, this paper intends to set the insurance period of rice temperature index insurance in this county from May 25 to September 25, and use the cumulative temperature data of this period to do the following research.

According to the average daily temperature (unit: Celsius) data of the county from 1998 to 2012, the cumulative temperature of each year from May 25 to September 25 in Wangqing County is calculated, and the cumulative temperature series $T_{i}(i=1,2, \ldots, 15)$ is obtained, in which $i=1,2, \ldots, 15$ means 1998, 1999,...respectively. The statistical results are shown in Table 3 below.

Table 3 Cumulative daily mean temperature for each year (in centigrade)

\begin{tabular}{|l|c|c|c|c|c|c|c|c|}
\hline Year & 1998 & 1999 & 2000 & 2001 & 2002 & 2003 & 2004 & 2005 \\
\hline $\begin{array}{l}\text { Cumulative } \\
\text { daily mean } \\
\text { temperature }\end{array}$ & 2188.1 & 2354.2 & 2444.4 & 2321.4 & 2182.8 & 2218.7 & 2319.1 & 2296.7 \\
\hline Year & 2006 & 2007 & 2008 & 2009 & 2010 & 2011 & 2012 & Average \\
\hline $\begin{array}{l}\text { Cumulative } \\
\text { daily mean } \\
\text { temperature }\end{array}$ & 2256.6 & 2340.4 & 2323.6 & 2140.4 & 2483.5 & 2302.6 & 2258.6 & 2295.41 \\
\hline
\end{tabular}

Since there are only 15 years of temperature data and the time interval is relatively short, the time trend of temperature is not obvious in this paper. At the same time, in order to simplify the calculation, this paper assumes that the temperature data obey independent and identical distribution and can be directly used for analysis.

Draw the data in Table 2 as a broken line graph and show it as shown in Figure 3 below. 


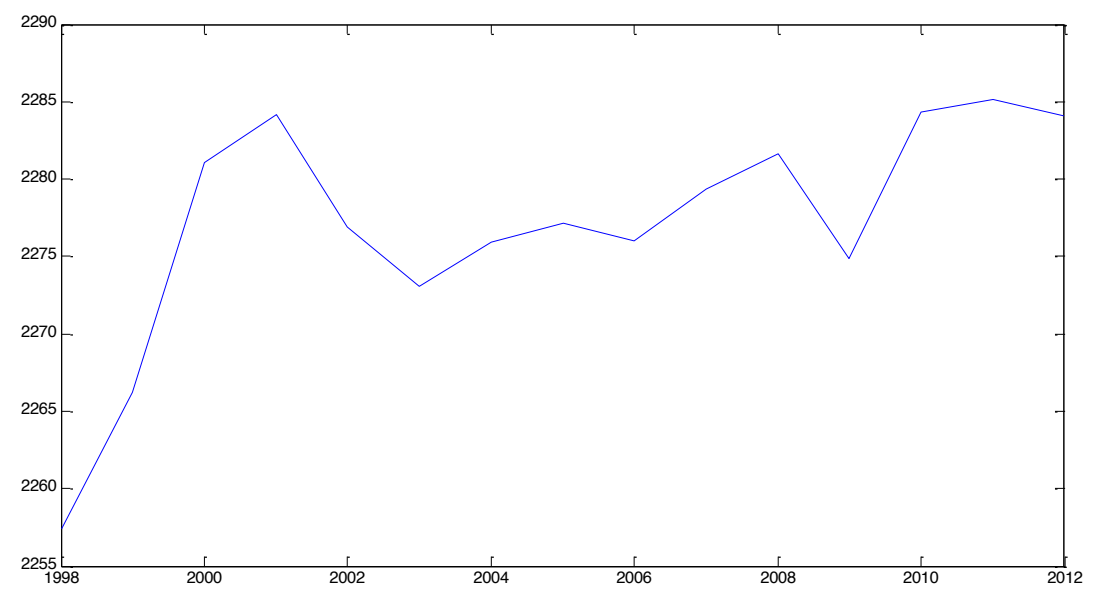

Figure 3 Statistics of cumulative daily average temp. in Wangqing County in 1998 to 2012

\section{Regression Analysis of cumulative Daily Average Temperature and Climate Yield}

In order to study the effect of temperature on rice climate yield, the most direct and simple way is to see the regression relationship between them. Through regression calculation, the results show that the cumulative daily average temperature variable has a weak explanation for the climate yield of rice, and it is not appropriate to use the cumulative daily average temperature directly to study the climate yield.

Because of the general understanding of crop growth habits and discussions with local agricultural experts, we believe that rice production is definitely related to temperature. So we can draw such a conclusion that either the quality of data is a big problem, or the specific indicators designed in this paper are not appropriate. Finally, through consulting the data and many attempts, this paper chooses the cumulative daily average temperature anomaly to study the climatic yield. The specific content is as follows.

\section{Cumulative daily average temperature anomaly}

Temperature anomaly refers to the difference between the cumulative daily average temperature and the total cumulative daily average temperature during the insurance period of each year. The calculation formula is as follows:

Temperature anomaly equals to the cumulative daily average temperature minus the total cumulative daily average temperature.

In which, the total cumulative daily average temperature is equal to the sum of cumulative daily mean temperature in all years divided by the number of years.

Calculated from the data in Table 2, the average cumulative daily average temperature is 2295.41. According to the above formula, the statistical results of annual anomalies are shown in Table 3 below. 
Table 3 Cumulative daily average temperature anomaly (in centigrade)

\begin{tabular}{|l|c|c|c|c|c|c|c|c|}
\hline Year & 1998 & 1999 & 2000 & 2001 & 2002 & 2003 & 2004 & 2005 \\
\hline Cum. daily mean temp. & 2188.1 & 2354.2 & 2444.4 & 2321.4 & 2182.8 & 2218.7 & 2319.1 & 2296.7 \\
\hline Cum. temp. anomaly & -107.31 & 58.79 & 148.99 & 25.99 & -112.61 & -76.71 & 23.69 & 1.29 \\
\hline Year & 2006 & 2007 & 2008 & 2009 & 2010 & 2011 & 2012 & Average \\
\hline Cum. daily mean temp. & 2256.6 & 2340.4 & 2323.6 & 2140.4 & 2483.5 & 2302.6 & 2258.6 & 2295.4 \\
\hline Cum. temp. anomaly & -38.81 & 44.99 & 28.19 & -155.01 & 188.09 & 7.19 & -36.81 & 0.00 \\
\hline
\end{tabular}

The data in Table 3 are presented as a broken-line graph, as shown in Figure 4 below.

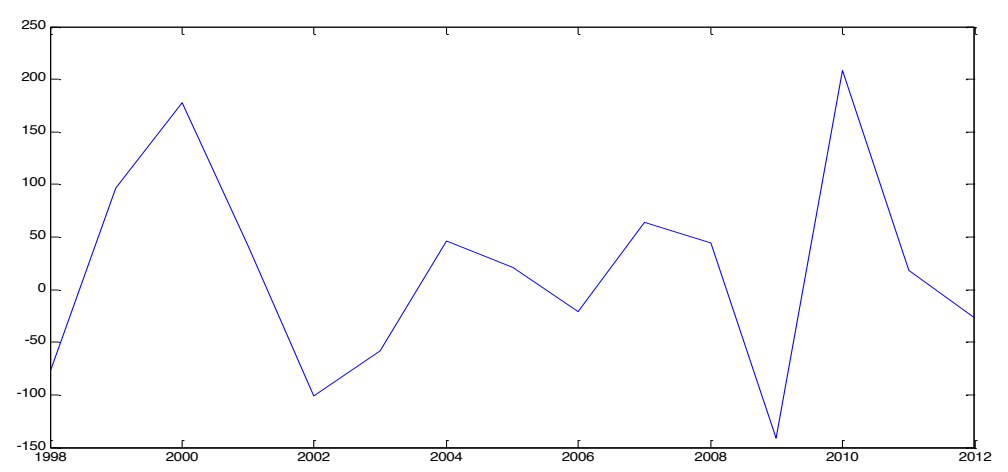

Figure4 Statistics of cum. daily average temp. anomaly in Wangqing County in 1998 to 2012

\section{Regression Analysis of Accumulated Daily Average Temperature Anomalies and Rice Climate Yield}

Using the least square estimation method, the cumulative daily mean temperature anomaly and rice climatic yield during the insurance period were estimated by econometric regression. The results are as follows.

$$
\begin{aligned}
& y_{t}=28.76167+0.62135 x_{t} \quad R^{2}=0.292739 \\
& (1.127993)(2.319650) \quad D W=2.013036
\end{aligned}
$$

In which,

$x_{t}$ is the accumulated daily average temperature anomaly in $t$ period (year).

$y_{t}$ is the average climatic yield of rice in period (year) $t$.

In parentheses are the statistics of each fitting value.

The following conclusions can be drawn from the regression results:

First, qualitatively, the slope of the regression equation is positive, that is to say, there is a positive correlation between the climatic yield of rice and the accumulated daily average temperature anomaly during the insurance period, which is consistent with our usual understanding of rice production. The higher the general temperature, the better the growth of rice and the higher the yield, especially in Northeast China.

Secondly, from a quantitative point of view, the cumulative daily average temperature anomaly during the insurance period has an effect of 0.62135 (kg/Celsius), i.e. the cumulative daily average temperature anomaly decreases by $0.62135 \mathrm{~kg}$ per hectare of land per unit (i.e. 1 Celsius). 


\section{Index Design and Trigger Value Selection}

In the foregoing, we have obtained the effect of temperature on rice yield. We can use temperature as a variable to design specific index based on the accumulated daily average temperature anomaly during the insurance period (drawing up 5.25-9.25). Then we need to determine the distribution of cumulative daily average temperature anomaly, and then choose insurable events and compensation criteria.

\section{Probability Distribution of cumulative Daily Average Temperature anomaly}

Using the cumulative daily mean temperature anomaly in Table 3 , a histogram is obtained, as shown in Figure 5.

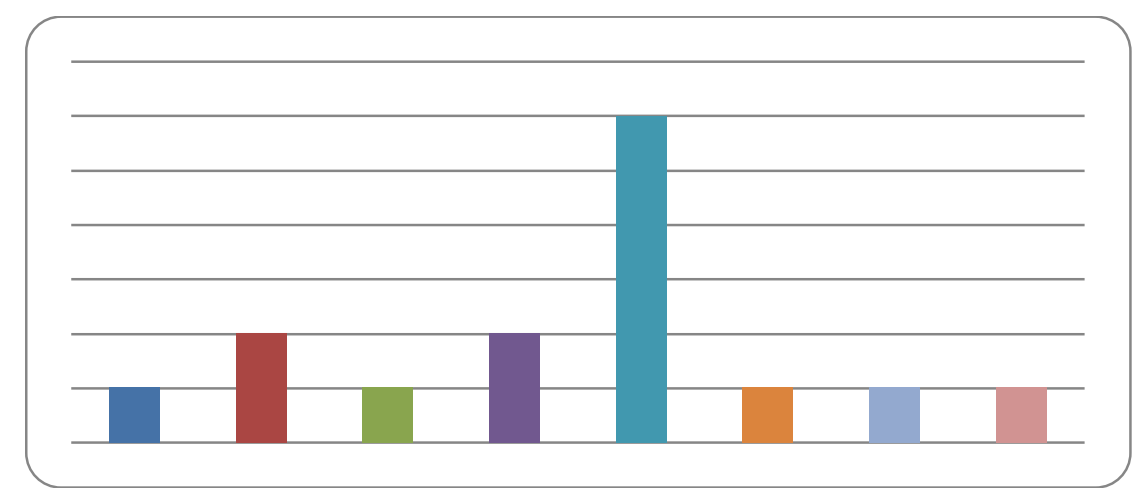

Fig. 5 Statistics of cum. temp. anomaly frequency (Celsius) in Wangqing in 1998 to 2012

As can be seen from Fig. 5, the probability distribution of cumulative daily mean temperature anomaly belongs to the peak and thick tail type, which is not completely left-right symmetry and has weak oscillation. It is not appropriate to choose normal distribution for fitting. Because of the limitation of data quantity, it is obvious that the error will be very large if a parameter distribution is used to fit. At this time, the non-parametric fitting method is considered in this paper. The non-parametric method can reflect the actual distribution of the original data more truly and accurately, without deliberately adjusting the data in order to obtain a certain distribution. It is more appropriate to use this method to fit the temperature data.

In this paper, the nuclear density method, which is most commonly used in non-parametric methods, is used to fit the accumulated daily average temperature anomaly. The nuclear density function is chosen as the Gauss nuclear density function, and its probability density distribution curve is drawn in Matlab, as shown in Figure 6 below.

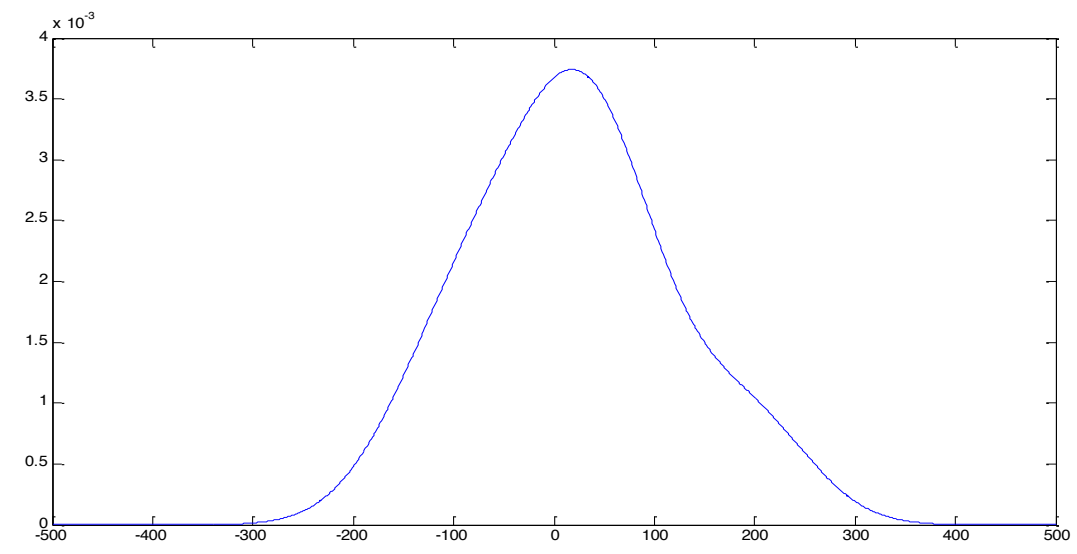

Figure 6 Cumulative temperature anomaly density distribution curve 
Based on Fig, 6, and using the distribution of quantile points to calculate the cumulative temperature anomaly under some relatively abnormal temperature conditions, the results are shown in Table 4.

Table 4 Abnormal cum. temperature anomaly in Wangqing County (Unit: Celsius)

\begin{tabular}{lccccc}
\hline & Once in 7 & Once in 8 & Once in 10 & Once in 15 & Once in 70 \\
& years & years & years & years & years \\
\hline Average tem. anomaly & -99 & -108 & -121 & -143 & -204 \\
\hline
\end{tabular}

\section{Trigger Value Selection}

From the point of view of insurable events, the temperature index insurance in this paper chooses to insure the loss of rice yield caused by relative abnormal temperature events that occur once in more than seven years. The compensation conditions set the upper and lower limit of 7-70 years, that is, more than 7 years before compensation, and when the abnormal temperature event is more than 70 years once, according to the temperature of 70 years once, the insurance amount is directly compensated. The reason for choosing abnormal temperature events occurring once in 7-70 years is that, on the one hand, considering the insurer's insurance ability, extreme temperature events occurring once in 70 years have great requirements on the insurer's insurance ability, and temperature events occurring once in 70 years belong to extreme temperature events, which are not common in reality; on the other hand, in order to control the strength of claims and reduce frequent claims cost, but also can reduce the premium, easier to market promotion.

Accordingly, the highest value of cumulative temperature anomaly events once in seven years is taken as the upper limit of temperature index (trigger value upper limit), and the highest value of cumulative temperature anomaly events once in 70 years is taken as the lower limit of temperature index (trigger value lower limit). In this way, the upper and lower limits of the temperature index can be obtained, which are -99 degrees Celsius and -204 degrees Celsius, respectively.

Only when the cumulative daily average temperature anomaly is in the interval $(-204,-99)$, can the insured person be compensated, and the compensation value is the product of the difference between the current year's anomaly value and the upper limit of the anomaly value, the influence of the cumulative daily average temperature anomaly on the climatic yield of rice and the market price of rice per kilogram. For example, if the cumulative daily average temperature anomaly calculated according to the data published by the local meteorological station in that year is 50 , the insured person will not be compensated. If the cumulative daily average temperature anomaly is - 117, the compensation $((-99)-(-117)) \times 0.62135 \times 3=33.55$ yuan will be paid per hectare.

\section{Rating, premium and claim rate calculation Pure Rate Formula}

Using the non-life insurance rating method, the pure rate calculation method is as follows:

Let the probability density function of cumulative daily mean temperature anomaly be $f(x)$ and the distribution function be $F(x)$. In which $x$ is the anomaly of cumulative daily average temperature for the year covered.

$$
\text { PureRate }=\frac{E[\text { loss }]}{\text { Benefit }}=\frac{\int_{\text {lower }}^{\text {upper }}(\text { upper }-x) f(x) d x}{\text { upper }- \text { lower }}+F(\text { lower })
$$


Based on the above non-parametric probability distribution and the formulas, the net premium rate of the rice temperature index insurance product is calculated to be $6.38 \%$.

\section{Pure premium calculation}

Pure Premium = PureRate $\mathrm{x}$ Benefit

\section{a) If the actual loss is the insured amount}

From the relationship between rice yield and cumulative daily average temperature anomaly, it can be seen that the cumulative daily average temperature anomaly will decrease by 0.62135 kg per unit area for every one degree centigrade decrease during the insurance period. The insurance product is designed to insure the cumulative daily average temperature anomaly fluctuation between 7 and 70 years, that is to say, the maximum fluctuation value is 105 degrees Celsius $(=(-99)-(-204))$. If the price of rice is set at 3 yuan per kilogram, the insurance amount is $0.62135 \times 105 \times 3=195.72525$ yuan, and the net premium is 12.48727 yuan (195.72525 x 6.38\%).

\section{b) If the amount of insurance is determined}

If the insurance amount is determined to be 300 yuan per hectare, the net premium will be 19.14 yuan per hectare from the net premium rate of $6.38 \%$.

\section{Gross Rate Formula}

Gross premium rate is the actual premium rate that the insured pays when purchasing insurance. On the basis of pure premium rate, gross premium rate takes into account the operating expenses of the company, the additional risks to future uncertainty and the expected profits of the company.

The gross rate determination formula is as follows:

$$
\text { GrossRate }=\frac{\text { PureRate } \times(1+\text { RiskLoading })}{1-\text { OperatingExpenseRate }}
$$

Because of the small amount of data and the poor quality of data and the high risk of pricing, this paper assumes a higher risk appendix when calculating gross premium rate; moreover, because weather index insurance is relatively new, it will necessarily require greater expenditure when listing and promoting in rural areas, so the assumption of operating cost rate in this paper is also higher. Assuming that the operating expense rate is $25 \%$ and the risk loading is $30 \%$ (including the company's expected profits), the gross premium of the rice temperature index insurance product is $6.38 \% \times(1+0.3) /(1-0.25)=11.06 \%$.

\section{Gross premium calculation}

Gross Premium = PureRate $\mathrm{x}$ Benefit

The gross premium is 21.65 yuan (195.72525 x $11.06 \%)$ if the actual maximum possible loss is chosen as the insurance amount.

The gross premium is 33.18 yuan per hectare $(300 \times 11.06 \%)$ if the insurance amount is chosen as the fixed value of 300 yuan. 


\section{The Measurement of Compensation Rate}

In this paper, the compensation rate is a simple concept of the ratio of insurance company's compensation expenditure to premium income. By calculating the compensation rate, it can provide reference and data support for insurance company's operation, risk management and solvency. For example, if the cumulative daily average temperature anomaly event occurs once in eight years, i.e. the anomaly value - 108, the difference between the trigger value upper limit and the anomaly value is $(-99)-(-108)=9$, and the compensation amount is $9 \times 300 \div 105=25.71$ yuan, with the compensation rate being $25.71 / 33.18=77.49 \%$. The specific compensation status is shown in Figure 7.

\begin{tabular}{|l|c|c|c|c|}
\hline $\begin{array}{l}\text { Abnormal } \\
\text { temperature }\end{array}$ & Anomaly & Upper- Anomaly & $\begin{array}{c}\text { compensation } \\
\text { amount }\end{array}$ & $\begin{array}{c}\text { compensation } \\
\text { rate }\end{array}$ \\
\hline Once in 7 yrs & -99 & 0 & 0 & $0.00 \%$ \\
\hline Once in 8 yrs & -108 & 9 & 25.71 & $77.49 \%$ \\
\hline Once in 10 yrs & -121 & 22 & 62.86 & $189.44 \%$ \\
\hline Once in 15 yrs & -143 & 44 & 125.71 & $378.89 \%$ \\
\hline Once in 70 yrs & -204 & 105 & 300 & $904.16 \%$ \\
\hline
\end{tabular}

Figure 7 The compensation status at abnormal temp. (with fixed benefit 300 as an example)

As can be seen, the insurance company has a higher compensation rate under the abnormal temperature condition which happens once in more than 15 years, especially the extreme temperature event which happens once in 70 years or called catastrophic weather event. Therefore, the insurance company should be prepared in advance and take risk management measures to deal with catastrophic risk.

\section{SUMMARY}

Based on the study of rice temperature index insurance in Wangqing County, a set of process for pricing weather index insurance is sorted out, and the concept of anomaly in meteorology is innovatively introduced into the design of temperature index, which has a good explanatory effect. When choosing trigger conditions, we select insurable events according to the fitted probability distribution and design the upper and lower limits of once-in-seven or 70-year events, which not only meets the insured's demand, but also is within the insurer's affordable range. It can be said that such product design pricing process can be directly applied to the use of weather index products of insurance companies.

In practice, in order to better implement weather index insurance, it is suggested that the government improve the policy support of agricultural insurance, strengthen the construction of meteorological stations and equipment updating, and pay attention to the training of compound talents. 


\section{Reference}

Cao. Innovation of Agricultural Insurance Products and Application of Weather Index Insurance [J]. Shanghai Insurance,2008,(8).

Mao Y D, Wu L H, etc. A reference design for citrus freeze damage insurance by using meteorological index in Zhejiang province[J]. Chinese Journal of Agrometeorology,2007,28(2).

Zhang H R. Index-based insurance contract-_-Innovation in agricultural insurance[J]. Journal of Central University of Finance and Economics, 2008(11):49-53.

Wu L H, Lou W P, etc. Design of products for rice agro-meteorological index insurance: a case in Zhejiang province [[J]. Scientia Agricultura Sinica,2010, 43 (23).

Lou W P, Wu L H, etc. Analysis and design of premium rates determined for weather-based index insurance contract of citrus[J]. Scientia Agricultura Sinica,2010 43 (9): 1904-1911.

Lou W P, Wu L H, Yao Y P. Design of weather-based indemniyu indice for paddy rice heavy rain damage insurance[J]. Scientia Agricultura Sinica,2010 43 (3):632-639.

Wang K, Zhang Q. Influence of flexible crop yield distributions on crop insurance premium rate: a case study on cotton insurance in three counties of Xinjiang province[J]. Journal of China Agricultural University,2010 (15) :114120.

Wang L H, Yang R H, etc..Maize GRP rate of premium deciding by nonparametric kernel density: a case study on Anguo city, Hebei province[J]. Journal of China Agricultural University,2007 (12) :90-94.

Chen X W. Application of agriculture weather index insurance in developing countries and its exploration in China [J]. Insurance Studies,2010(3):82-88.

Zhang X Q, Pan Y H. International practice of agro-climatic index insurance and implications for China[J]. Social science,2010 (1):58-63.

Xie S M, Mei Y Y. Operational mechanisms and actuarial pricing of weather derivatives[J]. The Theory and Practice of Finance and Economics,2011 32 (174) :39-43.

Wei H L, Wu R Q. Weather index insurance and sustainable development of agricultural insurance[J]. Finance \& Trade Economics,2010 (3):5-12.

Chen X F. The development, challenge and innovation of agriculture insurance: climate index insurance's experience worldwide and the role government playing[J]. Journal of Regional Financial Research,2012 (8) :62-67.

Li X X, Li H. Pricing Method of Weather Index Insurance [N]. China's insurance quote,2014-05-28 (2).

Casey Brown and James W. Hansen. Agricultural Water Management and Climate Risk[R]. Report to the Bill and Melinda Gates Foundation, 2008.

Skees, J.R., Haze1L, E. and Miranda, M. A New Approaches to Crop Yield Insurance in Developing Countries. International Food Policy Research Institute, EPTD Discussion PaperNo.55, November, 1999.

Ozaki, V .A., Ghosh, S.K., Goodwin, B. K. and Ricardo, S. Spatial-Temporal Modeling of Agricultural Yield Data with an Application to Pricing Crop Insurance Contracts [J].American Journal of Agricultural Economics. 2008,90:51961.

Ker A P, Goodwin B K. Non-parametric estimation of crop insurance rates revisited[J]. American Journal of Agricultural Economics, 2008, 3(3):463-478. 